\title{
A Re-Reflection to Protection Standards of International Intellectual Property In the Context of Climate-Friendly Technology Transfer
}

\author{
Jiani Jiang \\ Law School, Beijing Normal University, Beijing, 100875, PhD. Candidate, International trade law; \\ Visiting Research Associate, Environmental Policy Design Programs, Lehigh University \\ jianijiang@gmail.com
}

\section{Doi:10.5901/ajis.2014.v3n6p173}

\begin{abstract}
There is an unsettled debate regarding the role of intellectual property (IP) in the development and transfer of climate friendly technologies under the international climate negotiation. Such debate arises from distinct opinions on IP protection standards. It can worsen the solution of climate-friendly technology transfer to developing countries. This study aims to address the question of whether a premise for minimum protection standards exists in the international IP system combined with climate-friendly technology transfer. First, the basic problem of why international IP standards pose a threat to climate-friendly technology transfer is clarified. Second, three levels of arguments are applied to prove that the IP protection standard is not the only minimum requirement. The negative effects on the transfer of climate-friendly technology arise from ambiguous existing legal provisions and practices. Third, this study provides some suggestions for improvement for international IP standards accommodating the transfer of climate-friendly technology.
\end{abstract}

Keywords: Climate-friendly technology; Protection standards; International intellectual property rights

\section{Introduction}

It is widely believed that the international intellectual property (IP) system was established based on minimum protection standards; no upper limit was set. This lack of upper limit serves as a legitimate basis for raising the standards of IP in signing bilateral or regional trade agreements and profoundly affects the judgment of the dispute settlement body (DSB). However, excessively high IP standards nullify the flexible clauses on the promotion of public interests set in the international IP system. With regard to the actions tackling climate change, developing countries propose to refine such flexible clauses for climate-friendly technologies to be more easily transferrable. In the current negotiation of the United Nations Framework Convention on Climate Change (UNFCCC) on technology, numerous proposals were introduced to improve or establish a new international IP system that accommodates the transfer of climate-friendly technologies based on flexible clauses. However, the relationship between UNFCCC and Trade-Related Aspects of Intellectual Property Rights (TRIPS) is unclear. From the perspective of international laws, disputes mainly arise from the conflicting opinions of all parties with respect to the relationship between IP level and IP protection standards. Developed countries contend that enhancing IP will facilitate technology innovation and transfer. Hence, current standards should specify only the minimum requirements and not the ceiling. By contrast, developing countries argue that enhancing IP does not necessarily facilitate technology innovation and transfer. Thus, the existing protection standard should incorporate both the minimum and maximum requirements. Obviously, the international IP agreement under the framework of World Intellectual Property Organization (WIPO) and the TRIPS Agreement under the World Trade Organization (WTO) were set up based on the hypothesis that only minimum protection standards exist in the international IP system. (Ruse-Khan, H. G., 2009, p65) Hitherto, TRIPS-plus, an additional protection standard, was introduced in bilateral and regional trade agreements, which involve or are dominated by developed countries. Such requirement imposes further restriction on the applicable range of flexible clauses of TRIPS Agreement. Thus, developing countries clearly likely face the challenge from legislation in facilitating the transfer of climate-friendly technologies by taking advantage of the flexible clauses of TRIPS. 


\section{Transfer of Climate-Friendly Technologies and Minimum Protection Standards for IP}

\subsection{Definition of climate-friendly technologies}

Climate-friendly technologies have three features. Technically, climate-friendly technologies cannot be completely separated from traditional ones.For example, many technologies are versatile. They not only belong to the traditional technical classification but can also mitigate and adapt to climate change. The transfer of climate-friendly technologies should be conducted according to the legal norms applicable to the transfer of common manufacturing technologies. Currently, the TRIPS agreement under the WTO framework is the major legal norm that regulates the transfer of international technology. In terms of technical purpose, climate-friendly technologies, which are distinctive from ordinary manufacturing technologies, serve the interest of the public. Therefore, the provisions on the transfer of climate-friendly technologies in international trade should be differentiated from those on the transfer of ordinary technologies. The realization of the goals of addressing climate change should be prioritized. Most climate-friendly technologies are high technologies, in which developed countries take the lead. The ownership of patents on climate-friendly technologies throughout the world indicates that developed countries have a dominant advantage. A research by the European Patent Office in 2011 shows that the top six countries in clean energy technology patents, namely, Japan, USA, Germany, Korea, the United Kingdom, and France, account for $80 \%$ of the filings for global clean energy technologies. (UNEP, E. ICTSD, 2010, p30) Furthermore, the statistics on the flow of global technologies from the Organization for Economic Cooperation and Development indicate that most trades in climate-friendly technologies occur in developed countries. (Haščič, I. et al., 2010, p12) Therefore, the international IP system related to the transfer of climate-friendly technologies must consider the interests of the developing countries as the major recipient of technologies.

\subsection{Transfer of climate-friendly technologies and IP}

Most climate-friendly technologies exist in the form of patents and are actually transferred by IP licensing via commercial channels. (Wang S-P, Wang C, Xu Y-M et al., 2013, p16) From the legal perspective, the relationship between IP and the transfer of climate-friendly technologies can be summarized as follows. First, IP is the object in legal relationships related to the transfer of climate-friendly technologies. IP as a property right is protected by laws. The exchange of interests is possible by demarcating the boundaries between the economic interests of different parties. Thus, IP can be exchanged because of its private attribute. An international system built for IP renders such an exchange controllable. For this reason, intellectual property is the common target considered by two parties in the transfer of climate-friendly technologies. Second, the IP system provides a static legal premise for the transfer of climate-friendly technologies. The precondition for the smooth transfer of technologies is an explicitly established property system. What the IP system provides is the recognition and protection of the intangible assets of the owners, which is the static legal premise for the trades of climate-friendly technologies. The IP system profoundly affects the entire process: from the establishment of the ownership of climate-friendly technologies to the transfer of IP. It is a "regulator" of interest balance in the transfer of climate-friendly technologies between transferors and transferees.

\subsection{Current situation of the "minimum protection standards" for international IP}

The obligations under the TRIPS Agreement refer to the fundamental requirements for all WTO members as indicated by the minimum protection standards. (Taubman A., 2008, p935) In the contemporary international system of IP rights, the TRIPS Agreement plays the leading role and has incorporated IP protection into the international trade system for the first time. Thus, the legal relationship between IP and international technology transfer is formally established. Whether in developed countries or in developing countries, the criteria for international IP protection are closely connected to the basic obligations that should be fulfilled by the members who sign international agreements on IP. However, the articles of the TRIPS Agreement do not specify the means of promoting technology transfer through technology licensing. In fact, most of the articles of the Agreement only identify the goals of technology transfer to developing countries in an advocating manner. If no new measures are implemented to establish the role of IP in technology transfer, the IP factor will either directly or indirectly impede the transfer of climate-friendly technology from developed countries to developing countries in the battle against climate change. The minimum standards for international IP cannot be easily fulfilled by developing countries and the least-developed countries. These countries need to enhance the intensity of IP protection to fulfill the international agreements. Thus, the minimum protection standards established by the international IP system 
represent the extension of rights and the high-level protection of rights. Article 1.1 of the TRIPS Agreement generally defines only the minimum protection standards and not the maximum ones. The member states should not implement IP protection below the level required by the TRIPS Agreement but have the right to execute tighter IP protection. Moreover, the rules of the minimum protection standard are worded ambiguously. The TRIPS Agreement provides explicit provisions on the terms of protection, non-discriminatory treatment of foreign residents, and enforcement measures but fails to define in detail the standard of patentability. Lastly, "minimum protection standards" increase the possibility of abusive IP, including high licensing fees, refusal to deal, market control, and the permission of the licensor to own the majority of the company's shares.

The transfer of climate-friendly technologies is regulated by the international IP system. Except for a few clauses that mention the concept of "public interest," no explicit provisions indicating that "addressing climate change" is the public interest that deserves special considerations under this system exist. As a component of the one-package protocol of the WTO, the TRIPS Agreement applies to exceptional environmental terms, namely, paragraphs (b) and (g) of Article XX: General Agreement on Tariffs and Trade (GATT). With regard to the issue of climate-friendly technology transfer, the connection between the TRIPS Agreement and the exceptional environmental terms and their application ranges are difficult to identify. In particular, the existing exceptional environmental terms do not directly incorporate "the measures for facilitating the diffusion of climate-friendly technologies in response to climate change." Furthermore, the minimum protection standards provide considerable protection for IP in developed countries that already have an advantage. Developed countries take advantage of this condition to constantly raise the standards of IP protection. However, developing countries can hardly benefit from the system. Is it true that only minimum protection standards are established by the existing international IP system?

\section{Reflection on the "Minimum Protection Standards" in the International IP System}

\subsection{Is "minimum protection standard" equivalent to unlimited strong protection?}

The minimum standard for intellectual property protection was first formulated in Article 20 of the Berne Convention and later in Article 22 of the Rome Convention. Article 19 in the Paris Convention also contains similar provisions. The TRIPS Agreement unifies and defines the "minimum protection standards."(Article 1.1 of the TRIPS Agreement) The above provisions contain necessary restriction requirements that neither special protocol nor condition should not "contravene" or be a violation of the existing protocols, especially the second sentence in Article 1.1 of the TRIPS Agreement stating that "Members may, but shall not be obliged to, implement in their law more extensive protection than is required by this Agreement, provided that such protection does not contravene the provisions of this Agreement." Nevertheless, the clause of "minimum protection standard" in the TRIPS Agreement still arouses controversy in terms of its connotation. One point of view is that first half of this sentenceshould be emphasized, that is, the licensor has the right to introduce additional protection within the scope of the TRIPS Agreement. (Gervais, D. J, 2012, p98) Another point of view is that second half of this sentence is equally important. Its potential effect is to restrict the presence of TRIPS-Plus related to the non-discriminatory principle of the TRIPS Agreement and to the enforcement of IP because many clauses of the TRIPS Agreement imply that not only the lack of IP but also the abuse of IP will impede international trade. For example, "China - Measures Affecting the Protection and Enforcement of Intellectual Property Rights", in which part of criminal protection indicates that the panel holds that members have the right to decide on the legal system within its domain and the appropriate methods to implement this protocol as specified by Article 1.1 in the TRIPS Agreement. However, the panel also holds the opinion that the space of liberty granted to the members in this respect is only slightly considerable. The panel has the right to balance. (WTO, 2009, p115-116) Thus, Article 1.1 of the TRIPS Agreement does not allow for free discretion beyond the scope of minimum protection standards. Moreover, TRIPS Agreement does not provide a complementary explanation for such uncertainty but reserves the discretion to the panel.

The pacta sunt servanda in Article 26 of the Vienna Convention on the Law of Treaties (VCLT) indicates that the requirement of Article 1.1 of the TRIPS Agreement can be paraphrased as "the national law should respect the minimum standard for IP." The purpose of delineating the scope of Article 1.1 in TRIPS is to establish a more extensive IP system. Any form of TRIPS-Plus should not contravene the TRIPS Agreement. Setting the minimum standards for IP is sufficient to realize extensive IP. Thus, TRIPS-Plus, which is higher than the TRIPS Agreement, is allowed to take effect without restrictions; there is no risk of being contrary to the former agreement. However, this opinion deserves a thorough discussion. Article 1.1 of the TRIPS Agreement requires the national law to respect the minimum protection standard in TRIPS, which delineates the scope of obligations that the country should bear under the framework of TRIPS. Moreover, 
TRIPS-Plus contains coercive provisions on IP protection. If TRIPS-Plus is acquiesced to satisfy the minimum protection standard under the TRIPS Agreement, the scope of obligations that should be fulfilled by the country under the TRIPS Agreement will be broadened contrary to the purpose of the agreement. Thus, the minimum protection standard under TRIPS should not be considered unlimited. A ceiling on the scope of IP must be set.

\subsection{Does TRIPS-Plus conflict with the "minimum protection standard" under TRIPS?}

In the mid-1990s, the context for reaching the agreement on the protocols for international IP shifted from WIPO and WTO to free trade agreements (FTAs). Its relationship with the IP clauses presents a new feature, namely, the extension of TRIPS-Plus with FTAs as the major carrier. After the implementation of TRIPS, the international IP system featured the co-existence of several international IP protocols by TRIPS and WIPO under a multilateral trading system. In addition, the existing non-discriminatory global trade system and the "most favored nation" treatment principle became the pillars of WTO. Article 24 of GATT and Article 5 of the General Agreement on Trade in Services (GATS) permit FTAs with a preferential nature because developed countries that have entered WTO want developing countries to raise the level of IP to maintain their dominance in the technology trade. The extensive existence of TRIPS-Plus combined with the insufficient number of the "most favored nation" treatment principle and national treatment clauses under TRIPS has conflated the desire of the developed countries to raise the IP standards in international norm. Accordingly, the flexible clauses and the policy space under TRIPS are nullified by the obligations in TRIPS-Plus. Thus, disputes arise over the excessive restriction on national sovereignty, especially in the fields of climate change, public health, and knowledge acquisition. (Musungu, S. F., \& Dutfield, G., 2003, p16)

The clauses of TRIPS do not emphasize "contravene." Article 31.1 of VCLT states that "a treaty shall be interpreted in good faith in accordance with the ordinary meaning to be given to the terms of the treaty in their context and in the light of its object and purpose." Article 7 of TRIPS focuses on the interest balance between the innovator and user, and Article 8 is mainly about the public interest in important fields that can benefit the above judgment. Moreover, the declaration of the Doha round of the TRIPS Agreement and public health was passed in 2001. This declaration represents the consensus of the WTO members in this field: "in applying the customary rules of the interpretation of public international law, each provision of the TRIPS Agreement shall be read in the light of the object and purpose of the Agreement as expressed, in particular, in its objectives and principles." This declaration can be included in the "other factors" considered in interpreting the context under Article 31.3 (a) of VCLT. Articles 7 and 8 of the TRIPS Agreement indicate that the provision in TRIPS-Plus under FTAs that allows the raising of the standards for the protection of IP by a single party is a violation of the essence of the minimum protection standard under the TRIPS Agreement. The former is only favorable to the protection of the interests of the innovator or right holder and ignores the interests of the user; it also blocks the realization of public interests, such as the environment and health.

The word of "contravene" is explained as a kind of "Conflict with (a right, principle, etc.)" in Oxford dictionary. Pursuant to this, TRIPS-Plus and TRIPS conflicts with each other in terms of rights and principle. The question is, what is the "conflict" between norms? In the strictest sense, only direct incompatibility, that is, observing a necessary rule at the expense of other principles that constitutes a threat, can be regarded as a true conflict. The Appellate Body of WTO defines "conflict" in "Guatemala - Definitive Anti-Dumping Measure on Grey Portland Cement from Mexico" as a situation where adherence to the one provision leads to the violation of another. (WTO, 2000, p65) However, this opinion is not the only circulating opinion on conflicting norms. The generalized understanding is that conflict also exists when the right to free choice provided by the protocol cannot be fulfilled because of the restriction and impediment imposed by other obligations in the protocol. (Adarsh Ramanujan, 2009, p172) Therefore, if TRIPS-Plus restricts the freedom of WTO members to implement the flexible clauses of TRIPS, then it should be judged as conflicting with the TRIPS Agreement.

\subsection{How did the panel of DSB interpret form on "minimum protection standard"?}

In the WTO system, the Dispute Settlement Body (DSB) provides guarantee and predictability to the implementation of a multilateral trading system. To clarify the articles of the agreement, DSB provides a common, conventional interpretation as applied to national laws. Under DSB, the TRIPS Agreement is by far the most extensive multilateral agreement concerning IP. It is subject to the following constraints: jurisdiction imposed by the appealing body, restrictive agreement of the DSB, and execution of a series of vindictive measures against non-compliance. By far, the cases related to the clauses of the TRIPS Agreement on DSB have given rise to many interpretations by the panel report where the "threestep test" was employed. (WTO, 2000; WTO, 2000 (1); WTO, 2005) The cases related to the exceptional terms and 
restrictive clauses are the most remarkable. For instance, the panel utilized the three-step test to determine whether the exceptional clauses for patent apply in "Canada - Patent Protection of Pharmaceutical Products." They dismantled the original clause into three independent conditions. Article 30 establishes three conditions, which can only be applied in combination. However, each condition is independent from one another and should be met. The requirements in Article 30 are not fulfilled when one condition is unmet. The conclusion obtained is that the clause favors the economic interests of the right holder. In fact, the "limited exception" in Article 30 is not altogether separable from the other two conditions. Nevertheless, the separation of the three conditions for the purpose of analysis is not entirely impossible. However, such separation is difficult to be implemented in practice. Article 30 provides the major international law basis for exceptional clauses for patents in international trade. Its purpose is to restrict the additional provisions imposed by WTO members over the exceptional clauses for patents. As seen from the report by the panel, an attempt is made to dismantle Article 30 by the "three-step test." The test is then performed one by one. Given that the condition of limited exception as the first step is found to be in conflict from the beginning, the panel directly concludes that the clause fails to fulfill the original intention and favors the right holder.

Thus, the TRIPS Agreement fails to provide an explicit provision on security and predictability related to whether it agrees with the domestic exceptional clauses for IP. The reports by the panel only maintain the economic interests of the right holder through the "three-step test." The WTO members are not well informed on what to do but on what should not be done under a general context. These non-restrictive clauses assign a secondary place to the interests of the users. The only result is that TRIPS-Plus is an unlimited extension of IP at the expense of public interest. The ambiguity of the clauses and the requirement for the approval of the panel reduce the probability of the country to revise the new exceptional clauses according to the development level of the domestic economy, culture, and technology. This is not difficult for developed countries that have a long history of establishing exceptional rights. This issue poses a real challenge for developing and the least-developed countries, where IP protection and enforcement have relatively low intensity. The situation is aggravated by the lack of counterbalancing by the competition law. The ambiguity of the clauses restricts the developing and least-developed countries. The ambiguity of the IP clauses restricts the developing and leastdeveloped countries to adapt measures in the light of their needs. (A. Kur \& H. Grosse Ruse - Khan, 2008, 362)

The minimum protection standard in the IP system does not necessarily mean the absence of an upper bound constraint. However, the assumption that the minimum protection standard is not equipped with an upper limit has long prevailed because of the absence of an explicit regulation on upper limit. It also gave rise to that check and balance and protection of the interests and rights of users in the international IP system are almost non-existent. It is not unique, but has its counterpart. Currently, some FTAs contain special clauses on promoting technology transfer for the purpose of tackling climate change. In particular, FTAs have clauses for promoting the development of clean energy technology, which is closely related to mitigating climate change. The negotiations on Trans-Pacific Partnership and Transatlantic Trade and Investment Partnership implement a high global standard for IP protection in terms of labor use and the environment. Thus, the use of flexible clauses on IP by developing countries to acquire climate-friendly technologies will be further restricted. Based on the assumption of the minimum protection standards in the TRIPS Agreement, Article 27.1 only provides a general provision on the three conditions for patent application and allows the discretion by the country. Such freedom can give rise to many rubbish patents or the patent thicket phenomenon for one specific patent. Developed countries usually draw on this clause to formulate low conditions for patent application to consolidate their technical dominance. If developing countries adopt similar conditions, the only consequence is that the number of patents filed of the developed country worldwide will increase given the technical dominance of the developed country. Therefore, the entire patent system is monopolized by developed countries. Reflecting on the hazards brought by the minimum protection standard, the parties of developing countries in UNFCCC propose to draw on the flexible clauses of the TRIPS Agreement to refine the provisions. However, WTO is yet to respond to these suggestions. As indicated in the discussion above, the efforts of developing countries to draw on the flexible clauses of TRIPS face the huge risk of being crowded out by TRIPS-Plus. With respect to the issue of combating climate change and facilitating technology transfer, breaking the unreasonable assumption of the "minimum protection standards" for the international IP system will solve the dilemma associated with the transfer of climate-friendly technologies.

\section{Conclusion and Recommendation}

Through the legal analysis on the "minimum protection standard", it can be found that the assumption that the international intellectual property system only has "minimum standards of protection" does not hold. To popularize the climate-friendly technologies and to avoid the negative impact brought by the countries which have technology 
advantages from raising the standards of intellectual property protection, the inherent assumption that international intellectual property protection only has "minimum standards" needs to be revoked. The upper limit should be set for the standard of protection on the international level and in national legislation. The intellectual property protection standards and related systems should be repositioned and improved. To achieve the goal of promoting climate-friendly technology innovation and transfer, the exclusiveness of intellectual right property as a private right must be balanced by the consideration of the interests in the public domain. Therefore, the upper limit on the standard for intellectual property protection should be set. Through this means, the abuse of intellectual property can be prevented, and the interests of people other than the right owner will be protected, including the right of users, the right of free trade and public interests.

First of all, the TRIPS Agreement should clarify the general provision that the public interest mentioned in this protocol includes combating climate change. The innovation, transfer, and spread of climate-friendly technologies should be incorporated into the general provision and the public interest clause to legally support the unified international law related to the transfer of climate-friendly technologies in combating climate change. This will also clarify the connection with GATT XX. The articles for promoting climate-friendly technology innovation, transfer and dissemination should be incorporated into the general article and articles of public interests (Trips Agreement Article 7 and 8).

Second, a ceiling should be specified in Article 1.1. The standards for IP protection laid down by nations that are above the present protocol cannot contravene the exceptional provisions set to serve the public interests, such as combating climate change. The IP protection standards formulated of national IP laws should meet the ceiling requirements. When the exclusive rights to intellectual property are in conflict with the public's interests, priority should be given to the latter.

Lastly, the ceiling cannot be set by merely adjusting the clauses of the TRIPS Agreement. The assumption that the IP protection standards provide only the baseline should be changed; however, this process takes time and not only involves the revision of TRIPS by legislators but also the formulation of measures to impose the restriction on the ceiling through other means. Thus, the high standards laid down by TRIPS-Plus also need to have a ceiling. The attitude of the DSB panel toward the standards for IP protection also needs to be changed. A preventive review mechanism for the transfer of climate-friendly technologies should be established as follows: (1) a review mechanism should be set up for TRIPS-Plus clauses under FTAs and (2) an independent review mechanism should be set up for the opinions of the expert group with respect to the settlement of disputes on environmental cases (e.g., combating climate change).

To sum up, the suggestion for setting a ceiling is not equivalent to denying that protection above the minimum protection level is unreasonable. Nevertheless, the prerequisite, at the least, is that the public interest of combating climate change can be realized with priority under the flexible clauses for IP protection. The setting of the ceiling remains risky. Thus, one-size-fits-all provisions should be avoided in international institutions. Advanced legislation techniques should be employed on both international and national scales. A systematic arrangement is required in terms of institutional value and content. The international controversy that "the IP system impedes the transfer of climate-friendly technologies" triggers a more thorough reflection on the international IP system. The presumption that the international IP system only provides the minimum protection standard should be eliminated. Doing so is beneficial for finding the solution to establish a more reasonable legal system for the transfer of climate-friendly technologies. Further studies should focus on whether international and national legislations, including the IP system, facilitate the transfer of climate-friendly technologies to developing countries. Another issue is how to build and improve legislations for this purpose.

\section{Acknowledgment}

I am very grateful to the anonymous re-viewers. The study was financially supported by Beijing Normal University and the China Scholarship Council and the Society of International Economic Law (SIEL). I would also like to thank Professor John Martin Gillroy at Lehigh University, Professor Guihong Zhang at Beijing Normal University, Professor Can Wang at Tsinghua University, my classmates Xiaofang Wang and Haixin Tian, without whose assistance none of this work would have been possible.

\section{References}

Ruse-Khan, H. G. (2009), Time for a Paradigm Shift-Exploring Maximum Standards in International Intellectual Property Protection, Trade L. \& Dev., 1, 56-102.

UNEP, E. ICTSD, (2010). "Patents and Clean Energy: Bridging the Gap Between Evidence and Policy: Final Report". Geneva, Munich: United Nations Environment Programme (UNEP) Economics and Trade Branch, European Patent Office (EPO), International Centre for Trade and Sustainable Development (ICTSD). 
Haščič, I. et al. (2010), "Climate Policy and Technological Innovation and Transfer: An Overview of Trends and Recent Empirical Results", OECD Environment Working Papers, No. 30, OECD Publishing.

Wang S-P, Wang C, Xu Y-M et al., 2013: Intellectual Property Right and Climate Change, Sciences Academic Press (in Chinese).

Taubman A. Rethinking TRIPS: 'adequate remuneration' for non-voluntary patent licensing [J]. Journal of International Economic Law, 2008, 11(4): 927-970.

Gervais, D. J (2012). The TRIPS agreement: drafting history and analysis $43 \mathrm{~d}$ ed. London: sweet \& maxwell.

WTO, 2009: WT/DS362/R, China - Measures Affecting the Protection and Enforcement of Intellectual Property Rights, Report of the Panel.Musungu, S. F., \& Dutfield, G. (2003). Multilateral agreements and a TRIPS-plus world: the World Intellectual Property Organisation (WIPO). Quaker United Nations Office (QUNO).

WTO, 2000: WT/DS156/R .the Dispute Settlement Body adopted the Panel report on "Guatemala - Definitive Anti-Dumping Measures on Grey Portland Cement from Mexico. Adarsh Ramanujan.(2009). Conflicts Over "Conflict": Preventing Fragmentation of International Law, 1(1) TRADE L. \& DEV. 172 : 171-191.

WTO, 2000 (1): WT/DS160/R. Panel Report, United States - Section 110(5) of US Copyright Act (US - copyright).

WTO, 2005: WT/DS/174R. Panel Report, European Communities-Geographical Indications.03/15/2005

A. Kur \& H. Grosse Ruse - Khan. (2008), 'Enough is Enough - The Notion of Binding Ceilings in International Intellectual Property Protection', Intellectual Property in a Fair World Trade System: Proposals for Reform of TRIPS, Edward Elgar Publishing Limited.

Brewer T L. (2008). Climate change technology transfer: a new paradigm and policy agenda[J]. Climate Policy, 8(5): 516-526.

Correa, C. M. (2013). Innovation and Technology Transfer of Environmentally Sound Technologies: The Need to Engage in a Substantive Debate. Review of European Community \& International Environmental Law, 22(1), 54-61. 
